DOI: $10.17805 /$ zpu.2018.3.5

\title{
Военная безопасность России: актуальные проблемы
}

\author{
И. А. КРЫЛОВА \\ ИНСТИТУТ ФИЛОСОФИИ РАН
}

В статье дан анализ чрезвычайно сложной современной международной обстановки, чреватой нарастанием угрозы мировой войны. Показано, что нынешнее обострение военно-политической напряженности в мире связано со сменой технологических и мирохозяйственных укладов, вековых циклов накопления и глобальных игроков на международной арене.

Выделены основные признаки новой холодной войны против России: главное идеологическое противоречие - ориентация США и стран НАТО на сохранение однополярного мироустройства, ориентация России и союзников - на многополярный мир; наличие противоборствующих сторон: страны «золотого миллиарда» (блок НАТО) и страны, стремящиеся к установлению многополярного мира (БРИКС, Евразийский экономический союз, ШОС, ОДКБ); антагонистические цели: общая цель США и стран Запада - сохранение однополярного мира, частная цель - устранение основных геополитических противников, общая цель России и союзников - формирование многополярного мира, частная - обеспечение государственного суверенитета и национальной безопасности; ограниченные 
вооруженные конфликты; достижение политических целей военной силой; активизация военно-морских учений; новый этап гонки вооружений; экономические войны (санкции); приостановка сотрудничества России и НАТО.

Рассматриваются актуальные вопросы влияния расширения НАТО на обеспечение безопасности Российской Федерации. Исследуются четыре основных фактора, определяющих в настоящее время отношения НАТО и России: “украинский фактор», «кавказский фактор», «сирийский фактор», а также фактор «концентрации» в прибалтийских государствах (Литве, Латвии, Эстонии и Польше). Сделано заключение о постоянном риске эскалации противостояния, представляющего угрозу военной и национальной безопасности Российской Федерации.

Показана опасность разрабатываемых американскими стратегами концепций ограниченной ядерной войны и быстрого глобального удара, что негативно сказывается на обеспечении стратегической стабильности в современном мире.

Особое внимание уделяется уникальной автоматизированной, не имеющей аналогов в мире российской системе «Периметр», известной в Западной Европе и США как «Мертвая рука» (Dead Hand), которая гарантирует возможность нанесения ответного ядерного удара по противнику при любых обстоятельствах. Подчеркнуты преимущества данной системы перед имеющимися «дублирующими» аналогами в США и Великобритании. Сделан вывод о необходимости в условиях обострения конфронтации с Западом укрепления экономики и обороноспособности России для обеспечения военной и национальной безопасности, а также создания широкой антивоенной коалиции стран, способных остановить американскую агрессию.

Ключевые слова: Россия; США; НАТО; санкции; холодная война; концепция ограниченной ядерной войны; концепция быстрого глобального удара; система «Периметр»; Военная доктрина Российской Федерации; военная безопасность; национальная безопасность

\section{ВВЕАЕНИЕ}

$\mathrm{B}$ настоящее время человечество совершает самый крутой поворот в своей истории. «Рушится однополярный “Рах Americana”, основанный на гегемонии США, которые так и не смогли обеспечить стабильность и безопасность на Земле, - пишет $\Lambda$. Ивашов. - Планета на пороге радикального пересмотра принципов глобального мироустройства» (Ивашов, 2015: 3). Как показывает история, это обычно ведет к росту международной напряженности, военным конфликтам и мировым войнам. Современная цивилизация находится сейчас именно в таком состоянии. Происходящее ныне обострение международной военно-политической напряженности связано со сменой технологических и мирохозяйственных укладов, вековых циклов накопления и глобальных игроков на мировой арене. «Перенакопление капитала в США, - считает Г. Н. Смирнов, - ведет к небывалому экспансионизму, к глобальным претензиям, к роли мирового жандарма, к переоценке своих возможностей, к доминированию над союзниками, к потере реальных ориентиров и, в конечном счете, к авантюризму в мировой политике» (Смирнов, 2018: 153).

Надо сказать, что после крушения Советского Союза США оказались единственной сверхдержавой, которая благодаря своему превосходству в экономической, финансовой, интеллектуальной, научно-технической и военной сфере заняла господствующее положение в мире. «Экспансией Соединенных Штатов стало увеличение их влияния в сферах социальных отношений через современную глобализацию, - подчеркивает В. В. Шишков. - Глобализация стала формой имперского доминирования США в мире, предоставив в их распоряжение экономические, финансовые, интеллектуальные мировые ресурсы и поставив их самих в зависимость от успеха направленности и контролируемости этого процесса» (Шишков, 2014: 144). Нынешнее обострение международной ситуации показывает, что эпоха господства США как единствен- 
ной сверхдержавы заканчивается. Поэтому Соединенные Штаты стремятся сохранить свое лидерство путем развязывания мировой войны.

Следует признать, что в сложившейся ситуации новые вызовы и угрозы для России весьма серьезны. «Противостояние с Западом на Украине, в Арктике, угрозы с Востока, хаос на Ближнем Востоке, напор радикального ислама в Средней Азии и на Кавказе, Украинский кризис, - подчеркивает $\Lambda$. Ивашов, - лишь малая часть этой геополитической борьбы. Битва идет не за Украину, а за Россию, за Русский мир, за будущее всего человечества. В этой борьбе США пойдут на все, чтобы не дать возродиться России и возглавить процесс строительства нового миропорядка - более справедливого и безопасного. И Запад во главе с Соединенными Штатами бросает нам новый вызов» (Ивашов, 2015: 3). Аля того чтобы выстоять в условиях враждебности США и европейских стран, пролонгирования и ужесточения западных санкций, Россия должна стать экономически и технологически развитой, самодостаточной, что сделает ее независимой от внешних факторов.

Как пишет академик С. Глазьев, «объективно әскалация международной военнополитической напряженности обусловлена сменой технологических и мирохозяйственных укладов, в ходе которой происходит глубокая структурная перестройка экономики на основе принципиально новых технологий и новых механизмов воспроизводства капитала» (Глазьев 2016: 342-343; курсив источника. - И. К.). Существует и субъективная сторона антироссийской агрессии, вызванная независимым внешнеполитическим курсом Президента РФ В. В. Путина, который рассматривается как главная угроза доминированию США на мировой арене как единственной сверхдержаве (там же: 346).

В современных условиях Россия для Запада представляет серьезный геополитический вызов, а ослабление и уничтожение Российской Федерации (как в свое время СССР) является в конечном счете главной стратегической целью. Поэтому, исходя из анализа событий, произошедших в Косово, Афганистане, Ираке, Аивии, Центральной Азии, и всех «цветных революций» на границе с Россией, закономерно сделать вывод о том, что угроза агрессии против нашей страны существует. Причем мир России «столкнулся с очень серьезным вызовом - реальной угрозой войны и в прежних, и в новых форматах» (Иванов, Малинецкий, 2015: 36), что обостряет проблему обеспечения военной и национальной безопасности.

\section{НАЧАААСЬ НОВАЯ ХОАОАНАЯ ВОЙНА \\ ПРОТИВ РОССИИ ИАИ НЕТ?}

В связи с нарастанием агрессивности Запада, украинским конфликтом и антироссийскими санкциями философы, политологи и военные специалисты обсуждают вопрос: можно ли говорить о новой холодной войне против России? Представители либерального направления считают, что холодная война закончилась 30 лет назад победой США и Запада над СССР и миром социализма. Обстоятельный анализ холодной войны 1946-1991 гг. и особенностей ее нынешнего этапа между США и Россией дается в статье И. М. Ильинского «Холодная война: новый этап» (Ильинский, 2015). По мнению автора, ответ на вопрос о новом этапе холодной войны определяется пониманием типологии холодной войны как феномена не только ХХ в., но и всей истории человеческих войн. «По структуре своих целей холодная война, как и война «горячая», является одновременно войной политической, идеологической и дипломатической, войной за сырьевые ресурсы и рынки сбыта и т. А., - пишет И. М. Ильин- 
ский. - Однако принципиальное отличие холодной войны от «горячей» состоит в том, что холодная война - это прежде всего война геополитическая. Она - c перерывами на “горячие" битвы - может длиться десятилетиями, как холодная война 1946-1991 гг., а вообще - столетиями. И ее окончательный исход непредсказуем» (там же: 11). Поэтому мировая холодная война продолжается. И на новом этапе арессия США и Запада против России будет еще более ожесточенной. «Наличие антагонистических интересов и целей, беспрецедентное в XXI веке информационное противоборство, жесткие экономические санкции, начавшаяся гонка вооружений, - считает член-корреспондент РАН К. Сивков, - являются выраженными признаками холодной войны» (Сивков, 2015: 4). Автор выделяет ряд основных признаков холодной войны, которые, на наш взгляд, адекватно характеризуют нынешнюю реальность.

В первую очередь, это существующее антагонистическое противоречие между главными игроками на международной арене, которое является основной причиной начала новой холодной войны. В экспертном сообществе существует мнение, что в условиях отсутствия между Западом и Россией острых идеологических противоречий не может быть и холодной войны. Однако, на наш взгляд, прав К. Сивков, который утверждает, что если даже отсутствуют противоречия по социально-экономической системе (формально и у них, и у нас - капитализм), то в геополитическом аспекте такие противоречия существуют, причем они носят острейший характер. США и страны НАTO - за сохранение однополярного мироустройства, Россия, напротив, отстаивает идею многополярного мира. Фактически это основное идеологическое противоречие, которое и является главной причиной и определяющим признаком начала новой холодной войны в современных условиях.

Вторым признаком является наличие противоборствующих сторон. Если на предшествующем этапе холодной войны было два блока - НАТО и Организация Варшавского договора во главе с главными дидерами - США и СССР, то сегодня также существуют два противостоящих лагеря. С одной стороны, это США и страны «золотого миллиарда», претендующие на доминирование и глобальный контроль за природными ресурсами. С другой стороны - страны православной, исламской и других цивилизаций, которые ориентируются на многополярный мировой порядок. Одна из противоборствующих сторон имеет четкую организацию - это блок НАТО. Аругие страны, отстаивающие идею многополярного мироустройства, создали такие организации как БРИКС, Евразийский экономический союз (ЕАЭС), ШОС, ОАКБ.

Третий признак холодной войны - формулирование сторонами целей, которые должны быть антагонистическими. Если общей целью США и стран Запада является сохранение однополярного мира, а частная заключается в устранении главных геополитических противников - России и Китая, то общая цель для России и ее союзников состоит в формировании более справедливого многополярного мира, частной целью является обеспечение государственного суверенитета и национальной безопасности. Так как цели сторон являются антагонистическими, они достигаются, как правило, лишь военными средствами.

Четвертый признак холодной войны (по опыту противостояния США и СССР) ограниченные вооруженные конфликты, целью которых является завоевание более выгодных геополитических позиций. Целенаправленность действий США и НАТО по дестабилизации обстановки в различных регионах планеты свидетельствует о новом этапе холодной войны. В частности, «украинский конфликт», развязанный США, лишь часть хаотической гибридной войны против России. 
Пятым признаком холодной войны является достижение политических целей военной силой. Широкое использование информационной борьбы по линии Запад Восток является одним из признаков холодной войны. Что касается обычных вооружений, то они широко применяются в ограниченных военных конфликтах. В частности, в настоящее время США и Великобритания поставляют вооружение (нелетальное и летальное) украинским вооруженным силам. Что касается России, то наша страна выполняет Минские соглашения, оказывая дипломатическую поддержку Аонецкой народной республике и Ауганской народной республике, направляя в эти регионы гуманитарные конвои для мирного населения.

Шестым признаком холодной войны является активизация проведения военноморских учений. США такие учения все чаще проводят вблизи российских берегов. В ответ Россия вынуждена обеспечивать достаточное военно-морское присутствие в Атлантическом океане, Балтийском, Черном и Азовском морях, а также в Средиземном море.

Седьмой признак холодной войны - гонка вооружений. Показательно, что в XXI в. в Соединенных Штатах выделяются беспрецедентные средства для разработки и производства новейших видов вооружений. В условиях нарастания международной напряженности и агрессивности США и Запада военно-политическим руководством России поставлена задача ускоренной модернизации как обычных, прежде всего высокоточных вооружений, так и стратегических ядерных сил в целях обеспечения военной и национальной безопасности.

Восьмым признаком холодной войны могут считаться экономические войны. Введение и ужесточение западных санкций после вхождения Крыма в состав Российской Федерации представляют собой фактически полномасштабную экономическую войну. Из-за пролонгации западных санкций, обрушения цен на нефть и как следствие подрыва российской экономики наша страна была вынуждена принять ответные контрмеры.

И наконец, девятый признак холодной войны - свертывание большинства военных контрактов между Российской Федерацией и НАТО. К сожалению, в результате украинского кризиса и вооруженного конфликта на Аонбассе произошло резкое ухудшение отношений между Россией, США и НАТО, что привело к обострению геополитической обстановки в Европе. В результате сотрудничество России и НАТО временно приостановлено.

Причем после провокации Великобритании в связи с отравлением С. Скрипаля и его дочери в марте 2018 г. становится очевидным, что Россия и Запад вступают в эпоху новой холодной войны. Подтверждением этого является высылка после произошедшего инцидента 150 российских дипломатов из 28 европейских стран, в том числе 60 - из США (что лишь углубляет противостояние), которую Российская Федерация считает ошибкой. В ответ на агрессивные действия Запада Россия была вынуждена принять «зеркальные меры». Вместе с тем политическое руководство полностью отрицает какую-либо причастность России к совершенному преступлению, заявляя, что у Великобритании нет никаких доказательств. Аанный инцидент свидетельствует о том, что страны Запада, и в частности Великобритания, добиваясь своих целей, всеми силами стараются дискредитировать Россию в глазах мировой общественности. Это лишь подтверждает вывод о том, что между Западом и Востоком фактически началась новая холодная война, и ось этой войны проходит между Россией и НАTO. 


\section{ГЕОПОАИТИЧЕСКОЕ РАСШИРЕНИЕ НАТО}

\section{И ВОЕННАЯ БЕЗОПАСНОСТЬ РОССИИ}

В условиях обострения современной военно-политической ситуации угрозы национальной безопасности России со стороны НАТО достаточно серьезны. В Военной доктрине Российской Федерации сказано, что одной из основных внешних опасностей для страны является «наращивание силового потенциала Организации Североатлантического договора (НАТО) и наделение ее глобальными функциями, реализуемыми в нарушение норм международного права, приближение военной инфраструктуры стран - членов НАТО к границам Российской Федерации, в том числе путем дальнейшего расширения блока» (Военная доктрина Российской Федерации, 2014: Электронный ресурс).

Нынешние отношения России с НАТО объективно формируются рядом факторов. Один из них - «украинский фактор», сложившийся после вхождения Крыма в состав Российской Федерации в 2014 г. НАТО заявило, что Россия осуществила военное вмешательство на Украине, которое дестабилизировало обстановку не только на Украине, но и в евроатлантическом регионе. В результате по инициативе НАТО было приостановлено сотрудничество России и НАТО с апреля 2014 г. Уже в сентябре НАТО в связи с «украинским фактором» был предпринят ряд шагов.

Во-первых, странами - членами НАТО был утвержден документ - «План действий по обеспечению готовности HATO » (NATO Readiness Action Plan), который преАставляет собой всеобъемлющий пакет мер реагирования со стороны НАТО на «изменившиеся условия безопасности», связанные с политикой России у границ НАТО и за пределами стран - членов НАТО. Во-вторых, НАТО выступило с заявлением о том, что Россия осуществила незаконную «аннексию» Крыма, в связи с чем референдум, проведенный 14 сентября 2013 г. в Автономной Республике Крым (Украина), не может быть признан законным. В-третьих, было заявлено, что политика Российской Федерации в самопровозглашенных республиках $А \mathrm{HP}$ и $\Lambda \mathrm{HP}$ нарушает украинские законы и идет вразрез с Минскими соглашениями (Волохов, 2018: 122-123). Опасность состоит в том, что после воссоединения Крыма с Россией и обострения ситуации на Украине вновь возник очаг стратегической конфронтации в самом центре Евразии. Пришедшая в результате государственного переворота 2014 г. киевская власть постоянно требует от США поставок новейшего оружия для войны с Российской Федерацией. Украинский конфликт на границе с Россией, который представляет долгосрочный очаг нестабильности в Европе, сохраняет тенденцию его силового разрешения. Поскольку украинская сторона не выполняет Минские соглашения 2015 г. и продолжает военные действия против Аонбасса, это оказывает существенное влияние на формирование внешнеполитической национальной стратегии безопасности России.

Вторым является «кавказский фактор», создающий, по мнению НАТО, условия для дестабилизации региональных отношений, так как проводимая российская политика в отношении Грузии нарушает ее суверенитет и территориальную целостность. Поэтому страны НАТО не признают два договора России о союзничестве и стратегическом партнерстве с Республикой Абхазия (2014 г.) и Республикой Южная Осетия (2015 г.) Более того, США и НАТО оказывают Грузии (как и Украине) военную помощь.

Третий фактор - «сирийский». По существу, начиная с 2015 г. НАТО пытается доказать, что политика Российской Федерации в Сирии обусловлена стремлением наращивать военную мощь в данном регионе, военным вмешательством во внутренние 
дела страны, а также поддержкой существующего режима Б. Ассада. США предпринимают попытки «выдавить» Россию из Сирии. 14 апреля 2018 г. в нарушение Устава $\mathrm{OOH} \mathrm{и} \mathrm{международного} \mathrm{права} \mathrm{США} \mathrm{Великобританией} \mathrm{и} \mathrm{Францией} \mathrm{были} \mathrm{нанесены}$ удары по сирийскому городу Аума в связи с якобы имевшим там место применением химического оружия. Тогда весь мир пережил, по существу, ситуацию Карибского кризиса. Сирийскими средствами противовоздушной обороны, основу которой составляют комплексы ПВО советского производства, были успешно отражены удары авиационных и морских средств поражения (из 103 была перехвачена 71 крылатая ракета). По словам начальника главного оперативного управления Генштаба Вооруженных сил РФ генерал-полковника С. Руцкого, удар США и их союзников по Сирии явился «реакцией коалиции на успехи республики в борьбе с международным терроризмом...» (Генштаб ВС РФ: ... : Электронный ресурс). В ответ на агрессивные действия США, Великобритании и Франции Россия поставит в Сирию комплексы С300 для обеспечения безопасности в этом регионе.

По существу, начиная с 2014 г. эти три фактора - «украинский», «кавказский» и «сирийский»- стали активно использоваться НАТО «в обоснование своей политики “конфронтационных разногласий” с Российской Федерацией и повлияли на стремление НАТО приблизить свою военную инфраструктуру в непосредственной близости у государственных границ Российской Федерации» (Волохов, 2018: 123).

Не меньшее значение имеет также фактор «концентрации» в прибалтийских странах - Эстонии, Аатвии, Аитве и Польше военной техники и военных сил в численности, значительно превышающей времена Второй мировой войны. Несмотря на заверения западных политиков о том, что НАТО не представляет угрозы России, расширение альянса не только продолжается, но инфраструктура НАТО (военная, оборонная, штабная, стратегическая) находится в «активном состоянии». Причем вызовы и угрозы со стороны блока НАТО оказывают существенное влияние на развитие международных отношений. А поскольку в политике НАТО «фактор силы» не снижается, то стремление НАТО к созданию и развертыванию новых видов наступательных вооружений ведет к ослаблению заключенных ранее договоров и соглашений в области контроля над вооружением. Более того, существует постоянный риск әскалации противостояния, что представляет угрозу военной и национальной безопасности России.

\section{АМЕРИКАНСКИЕ КОНЦЕПЦИИ ОГРАНИЧЕННОЙ ЯАЕРНОЙ ВОЙНЫ И БЫСТРОГО ГАОБААЬНОГО УААРА}

В настоящее время Соединенными Штатами принята новая ядерная стратегия, которая допускает превентивный ядерный удар в ответ даже на неядерную угрозу и кибератаки. В Военной доктрине Российской Федерации, подписанной Президентом РФ В. В. Путиным 26 декабря 2014 г., подтверждается готовность России применить ядерное оружие даже в случае безъядерной агрессии, угрожающей национальной безопасности и существованию государства (Военная доктрина Российской Федерации, 2014: Электронный ресурс).

Известно, что сегодня в США продолжается разработка различных сценариев ограниченной ядерной войны против России. Показателен в этой связи последний инцидент, произошедший в марте 2018 г. с американской подводной лодкой, застрявшей во льдах Арктики во время учений, целью которых была «отработка» нанесения ядерного удара по России, обнаруженной российскими специалистами, что свидетельствует о незавершенности системы обеспечения ядерной безопасности в мире. 
К сожалению, современное поколение государственных деятелей и политиков говорит о ядерном как об обычном оружии. Конечно, в XXI в. огромная мощь ядерного оружия продолжается оставаться «сдерживающим фактором в развязывании войн», - подчеркивает Н. П. Рябченко. «Тем не менее вероятность их возникновения, как локальных, так и более крупных, в том числе атомных, сохраняется» (Рябченко, 2016: 94-95). А значит, сохраняется и угроза глобальной катастрофы на планете и уничтожения жизни на Земле, что было доказано еще в 1983 г. советскими и американскими учеными в результате разработки концепции «ядерной зимы» (Стенчиков, 2003: 1298-1300).

Наряду с разработкой различных сценариев ограниченной ядерной войны в последние годы в США повышенное внимание уделяется концепции уничтожения Стратегических сил России в первом глобальном ударе обычными (неядерными) зарядами высокоточных крылатых ракет большой дальности морского базирования. Это оружие направлено на уничтожение командных пунктов, пусковых установок стратегических ракет с ядерными боеголовками, объектов противовоздушной и противокосмической обороны, аэродромов и т. д.

Приходится констатировать, что в XXI в. в условиях обострения огромного количества общечеловеческих проблем: бедности, голода, дефицита пресной воды, загрязнения окружающей среды, негативных изменений климата, истощения природных ресурсов, непредсказуемости стихийных бедствий, возникновения новых болезней, нарастания астероидной опасности и др. - борьба между странами за лидерство на международной арене становится все более ожесточенной. Последние два десятилетия показали, что в этой борьбе важную роль продолжает играть военно-политический фактор. «Причем во многих случаях в качестве важного средства обеспечения суверенитета рассматривается ядерное оружие, - подчеркивает А. А. Кокошин. Это демонстрируют такие государства, как КНР, Индия, Пакистан, Израиль, КНАР» (Кокошин, 2014: 197-198).

Все это свидетельствует о том, что в XXI в. ядерное сдерживание сохранит свое место в системе инструментов национальной политики как военное средство предотвращения войны.

\section{«ПЕРИМЕТР - СИСТЕМА ГАРАНТИРОВАННОГО \\ ОТВЕТНОГО ЯАЕРНОГО УААРА}

Очевидно, что в связи с обострением международной ситуации модернизация Вооруженных сил РФ является главным условием обеспечения военной и национальной безопасности. Поэтому военно-политическим руководством страны были выделены беспрецедентные финансовые и другие ресурсы для повышения боеспособности Вооруженных сил РФ и средств сдерживания потенциальной военной агрессии против России. Аостигнутые успехи в ускоренной модернизации обычных вооружений, а также стратегических ядерных сил России были наглядно продемонстрированы 1 марта 2018 г. в Обращении Президента России В. В. Путина к Федеральному Собранию.

Это вызвало настоящую истерию на Западе. Особенно сведения о модернизации уникальной, не имеющей аналогов в мире полностью автоматизированной системы «Периметр». Аанная система, известная в Западной Европе и США как «Мертвая рука» (Dead Hand), была создана в СССР еще в период холодной войны (поставлена на боевое дежурство в 1985 г. и снята с боевого дежурства в 1995 г.). «Периметр» является комплексом автоматического управления массированным ответным ядерным 
ударом по противнику при любых обстоятельствах. «По США все равно будет нанесен удар возмездия» (Система ответного ..., 2017: Электронный ресурс). Отличительной чертой «Периметра» является способность доведения боевых приказов, исходящих от Генерального штаба и Управления РВСН до всех командных пунктов и установок даже в случае гибели высшего военно-политического руководства страны либо полного уничтожения линий связи.

Следует напомнить, что в США еще 3 февраля 1961 г. была создана и введена в действие система «Операция Зазеркалье» (Operation Looking Glass). Основой системы служили воздушные командные пункты Стратегического авиационного командования США, которые были развернуты на базе одиннадцати самолетов Boeing EC-135C, находившихся в воздухе 24 часа в сутки. Их боевое дежурство продолжалось с 1961 г. по 24 июня 1990 г. (там же). В США также существовал похожий по предназначению на «Периметр» комплекс передачи приказа о запуске - Аварийная система ракетных коммуникаций (Emergency Rocket Communications System).

Британский аналог российской системы - «Письма последней инстанции» (Letters of Last Resort) представляют собой письменные распоряжения премьер-министра с приказами для командования подводных лодок, оснащенных ядерными ракетами «Трайдент». В них содержатся распоряжения о том, какие действия следует предпринять в случае гибели британского правительства в результате ядерного удара. Письма хранятся в двух сейфах на каждой из подводных лодок и уничтожаются, когда очередной премьер-министр покидает свой пост (Corriere Della Sera. ... , 2017: Электронный ресурс).

Надо сказать, что система «Периметр» создавалась как резервная система связи, если вдруг система «Казбек» («ядерный чемоданчик»), либо линии связи РВСН окажутся уничтоженными первым ударом, согласно концепции ограниченной ядерной войны. Поэтому система была спроектирована как полностью автоматическая, способная принять решение об ответном ударе «без человека». Поэтому «Периметр»является фактором сдерживания, т. е. дает реальные гарантии отказа агрессора от сокрушительного превентивного удара. Брюс Блэр (Bruce Blair), бывший сотрудник ВВС США по запуску ядерных ракет, один из ведущих мировых специалистов по ядерному разоружению, сооснователь Международного движения за Глобальный ноль (Global Zero), полагает: «...существование подобного оружия на самом деле помогает снизить риск ядерной войны. Работающая “Мертвая рука” означает, что Западу всегда нужно будет подумать дважды, когда у него возникнет искушение нанести ядерный удар» (Полунин, 2018: Электронный ресурс). Эта уникальная система полностью исключает возможность принятия высшим военно-политическим руководством страны необдуманного решения об ответном ударе как из-за ложной тревоги, так и из-за непроверенной информации. В настоящее время отечественная система двойного резервирования «Периметр» модернизирована и «работает». Она гарантирует возможность нанесения ответного ядерного удара по агрессору даже при полном уничтожении линий связи и командных пунктов российских стратегических ядерных сил. Причем даже в случае мгновенного глобального неядерного удара по противнику будет нанесен удар возмездия. Так, для уничтожения такой страны, как США, вполне достаточно 200 современных ядерных зарядов.

Однако при всей значимости ядерного сдерживания в современных условиях оно не является панацеей в обеспечении военной и национальной безопасности Российской Федерации. «Ядерной мощью можно лишь частично компенсировать слабость 
в экономической и политической области, в развитии технологий и сил общего назначения, - подчеркивает академик А. А. Кокошин. - Поэтому ядерное сдерживание необходимо дополнить эффективным стратегическим неядерным (предъядерным) сдерживанием с использованием высокоточного дальнобойного оружия в неядерном оснащении» (Кокошин, 2014: 204).

То есть на современном этапе стратегическое неядерное сдерживание должно стать дополнением к стратегическому ядерному сдерживанию. И над этими задачами работает ныне российский ВПК.

\section{ЗАКАЮЧЕНИЕ}

Оценка сложившейся напряженной международной ситуации, деятельности НАТО и характера новой военной доктрины США показывает, что потенциальная угроза войны против России существует. Исходя из этого, Президент РФ В. В. Путин поставил задачу ускоренной модернизации Вооруженных сил России для обеспечения военной и национальной безопасности. Наряду с укреплением боеготовности страны перед Россией встает задача консолидации всех прогрессивных сил и создания широкомасштабной антивоенной коалиции государств для предотвращения новой мировой войны. Такие коалиции всегда играли огромную роль в истории. В настоящее время в международную антивоенную коалицию могли бы войти как европейские страны, так и страны БРИКС, Корея и страны Индокитая, страны Ближнего и Среднего Востока, латиноамериканские и развивающиеся страны «Группы 77», т. е. все страны, которые выступают против войн за справедливый мировой порядок (Глазьев, 2015: 209-212).

Таким образом, в условиях нарастания агрессии Запада и непредсказуемости действий США и НАТО, игнорирующих Устав ООН и нормы международного права, России необходимо консолидировать вокруг себя антивоенные силы, форсированными темпами укреплять экономику и обороноспособность страны для обеспечения военной и национальной безопасности.

\section{СПИСОК АИТЕРАТУРЫ}

Военная доктрина Российской Федерации (2014) [Электронный ресурс]// Российская газета. 30 декабря. URL: https://rg.ru/2014/12/30/doktrina-dok.html (дата обращения: 15.02.2018).

Волохов, В. И. (2018) Обеспечение национальной безопасности Российской Федерации в условиях геополитического расширения НАТО // Россия в условиях изменяющегося мира. Философия осмысления и перспективы будущего : сб. науч. ст. / отв. ред. В. Н. Ксенофонтов, М. Ш. Гунибский. М. : Проспект. 192 с. С. 122-130.

Генштаб ВС РФ: средства ПВО Сирии перехватили 71 ракету из 103 [Электронный ресурс] // ИТАР ТАСС. 14 апреля. URL: http://tass.ru/armiya-i-opk/5125673 (дата обращения: 14.04.2018).

Глазьев, С. (2015) Украинская катастрофа: от американской агрессии к мировой войне? М. : Книжный мир. 352 с.

Глазьев, С. (2016) Экономика будущего. Есть ли у России шанс? М. : Книжный мир. 640 с.

Иванов, В., Малинецкий, Г. (2015) Наука и войны будущего (доклад Изборскому клубу) // Изборский клуб. №5 (29). С. 6-37.

Ивашов $\Lambda$. (2015) Битва за Россию. Хроники геополитических сражений. М. : Изборский клуб ; Книжный мир. 416 с.

Ильинский, И. М. (2015) Холодная война: новый этап // Знание. Понимание. Умение. № 3. C. $5-17$.

Кокошин, А. А. (2014) Стратегическое ядерное и неядерное сдерживание: приоритеты современной эпохи // Вестник РАН. Т. 84. № 3. С. 195-205. 
Полунин, А. (2018) «Мертвая рука» Кремля снова держит Запад за горло [Электронный ресурс]// Свободная пресса. 29 марта. URL: https://svpressa.ru/war21/article/196551/ (дата обращения: 30.03.2018).

Рябченко, Н. П. (2016) Войны: нерешенная проблема человечества // Век глобализации. №3. С. $85-96$.

Сивков, К. (2015) Во главе антизападной коалиции. Идет война холодная, гибридная война // Военно-промышленный курьер. 18-24 марта. № 10 (576). С. 1-4.

Система ответного ядерного удара «Периметр» (2017) [Электронный ресурс] // Военное обозрение. 23 октября. URL: https://topwar.ru/127861-perimetr-sistema-otvetnogo-yadernogoudara.html (дата обращения: 05.03.2018).

Смирнов, Г. Н (2018) Внешняя политика и идеология в российско-американских отношениях: исторические параллели // Россия в условиях изменяющегося мира. Философия осмысления и перспективы будущего : сб. науч. ст. / отв. ред. В. Н. Ксенофонтов, М. Ш. Гунибский. М. : Проспект. 192 с. С. 144-154.

Стенчиков, Г. А. (2003) Ядерная зима // Глобалистика : энциклопедия / гл. ред. И. И. Мазур, А. Н. Чумаков. М. : ЦНПП «Аиалог»; ОАО «Радуга». 1328 с. С. 1298-1300.

Шишков, В. В. (2014) Становление и развитие гегемонии США: имперское доминирование и глобализация в XX в. // Век глобализации. №1 (13). С. 133-146.

Corriere Della Sera. Ядерная война будущего (2017) [Электронный ресурс] // ИНОСМИ. 19 сентября. URL: https://inosmi.ru/military/20170619/239618267.html (дата обращения: 02.03.2018).

Aата поступления: 15.05 .2018 2.

\section{MILITARY SECURITY OF RUSSIA: URGENT ISSUES}

\section{A. KRYLOVA}

RAS INSTITUTE OF PHILOSOPHY

The article analyses the extremely complex contemporary international situation, fraught with the growing threat of a world war. It is shown that the current aggravation of military and political tensions in the world is associated with a change of technological and world economic patterns, secular accumulation cycles and global players on the international stage.

The main features of the new Cold War against Russia are singled out: the main ideological contradiction - orientation of the USA and NATO countries to preserve a uni-polar world order, Russia and its allies - to preserve a multi-polar world; the presence of confrontational parties - countries of the "Golden Billion" (NATO bloc) and countries striving to establish a multi-polar world (BRICS, Eurasian Economic Union, SCO, CSTO); the antagonistic purposes: the common purpose of the USA and Western countries - preservation of a uni-polar world, private purpose - elimination of the main geopolitical opponents, the common purpose of Russia and its allies - formation of a multipolar world, private - ensuring state sovereignty and national security; the limited armed conflicts; the achievement of political goals by military force; the activation of naval exercises; the new phase of the arms race; the economic wars (sanctions); the suspension of cooperation between Russia and NATO.

The article considers the current issues of the influence of NATO expansion on the security of the Russian Federation. It studies The four main factors that determine the current relationship between NATO and Russia: the "Ukrainian factor", the "Caucasian factor", the "Syrian factor", and the factor of "concentration" in the Baltic States (Lithuania, Latvia, Estonia, and Poland) as well. The author draws a conclusion about the constant risk of escalating confrontation, which is a threat to the military and national security of the Russian Federation.

The article demonstrates the danger of the concepts that are being developed by American strategists: those of a limited nuclear war and a rapid global strike, which has a negative impact on the provision of strategic stability in the modern world. 
Particular attention is paid to the unique automated Russian system "Perimeter", known in Western Europe and the United States as the "Dead Hand", which has no analogues in the world and guarantees the possibility of a retaliatory nuclear strike against the enemy under any circumstances. The article emphasises the advantages of this system in comparison with other existing "duplicating" systems in the USA and UK. The author concludes that, in conditions of aggravating confrontation with the West, it is necessary to strengthen Russia's economy and defense capability to ensure military and national security; and to create a broad anti-war coalition of countries capable of stopping the American aggression.

Keywords: Russia; USA; NATO; sanctions; Cold War; concept of limited nuclear war; concept of rapid global strike; "Perimeter" system; military doctrine of the Russian Federation; military security; national security

\section{REFERENCES}

Voennaia doktrina Rossiiskoi Federatsii (2014). Rossiiskaia gazeta, 30 December [online] Available at: https://rg.ru/2014/12/30/doktrina-dok.html (access date: 15.02.2018). (In Russ.).

Volokhov, V. I. (2018) Obespechenie natsional'noi bezopasnosti Rossiiskoi Federatsii v usloviiakh geopoliticheskogo rasshireniia NATO. In: Rossiia v usloviiakb izmeniaiushchegosia mira. Filosofiia osmysleniia i perspektivy budusbchego : collection of scientific articles / ed. by V. N. Ksenofontov and M. Sh. Gunibskii. Moscow, Prospekt. 192 p. Pp. 122-130. (In Russ.).

Genshtab VS RF: sredstva PVO Sirii perekhvatili 71 raketu iz 103. ITAR TASS, 14 April [online] Available at: http://tass.ru/armiya-i-opk/5125673 (access date: 14.04.2018).

Glaz'ev, S. (2015) Ukrainskaia katastrofa: ot amerikanskoi agressii k mirovoi voine? Moscow, Knizhnyi mir. 352 p. (In Russ.).

Glaz'ev, S. (2016) Ekonomika budushchego. Est' li u Rossii shans? Moscow, Knizhnyi mir. 640 p. (In Russ.).

Ivanov, V. and Malinetskii, G. (2015) Nauka i voiny budushchego (doklad Izborskomu klubu). Izborskii klub, no. 5 (29), pp. 6-37. (In Russ.).

Ivashov L. (2015) Bitva za Rossiiu. Kbroniki geopoliticheskikb srazbenii. Moscow, Izborskii klub; Knizhnyi mir. 416 p. (In Russ.).

Il'inskii, I. M. (2015) Kholodnaia voina: novyi etap. Znanie. Ponimanie. Umenie, no. 3, pp. 5-17. (In Russ.).

Kokoshin, A. A. (2014) Strategicheskoe iadernoe i neiadernoe sderzhivanie: prioritety sovremennoi epokhi. Vestnik RAN, vol. 84, no. 3, pp. 195-205. (In Russ.).

Polunin, A. (2018) «Mertvaia ruka» Kremlia snova derzhit Zapad za gorlo. Svobodnaia pressa, 29 Mars [online] Available at: https://svpressa.ru/war21/article/196551/ (access date: 30.03.2018). (In Russ.).

Riabchenko, N. P. (2016) Voiny: nereshennaia problema chelovechestva. Vek globalizatsii, no. 3, pp. 85-96. (In Russ.).

Sivkov, K. (2015) Vo glave antizapadnoi koalitsii. Idet voina kholodnaia, gibridnaia voina. Voennopromyshlennyi kur'er, 18-24 Mars, no. 10 (576), pp. 1-4. (In Russ.).

Sistema otvetnogo iadernogo udara «Perimetr» (2017). Voennoe obozrenie, 23 October [online] Available at: https://topwar.ru/127861-perimetr-sistema-otvetnogo-yadernogo-udara.html (access date: 05.03.2018). (In Russ.).

Smirnov, G. N. (2018) Vneshniaia politika i ideologiia v rossiisko-amerikanskikh otnosheniiakh: istoricheskie paralleli. In: Rossiia $v$ usloviiakb izmeniaiushchegosia mira. Filosofiia osmysleniia $i$ perspektivy budushchego : collection of scientific articles / ed. by V. N. Ksenofontov and M. Sh. Gunibskii. Moscow, Prospekt. 192 p. Pp. 144-154. (In Russ.).

Stenchikov, G. L. (2003) Iadernaia zima. In: Globalistika : encyclopedia / chief editor I. I. Mazur and A. N. Chumakov. Moscow, TsNPP «Dialog»; OAO «Raduga». 1328 p. Pp. 1298-1300. (In Russ.).

Shishkov, V. V. (2014) Stanovlenie i razvitie gegemonii SShA: imperskoe dominirovanie i globalizatsiia v XX v. Vek globalizatsii, no. 1 (13), pp. 133-146. (In Russ.). 
Corriere Della Sera. Iadernaia voina budushchego (2017). INOSMI, 19 September [online] Available at: https://inosmi.ru/military/20170619/239618267.html (access date: 02.03.2018).

Submission date: 15.05.2018.

Крылова Ирина Анатольевна - доктор философских наук, ведущий научный сотрудник сектора философских проблем политики Института философии РАН. Адрес: 109240, Россия, г. Москва, ул. Гончарная, А. 12, стр. 1. Тел.: +7 (495) 697-91-89. Эл. адрес: tatyanawings@gmail.com

Krylova Irina Anatolyevna, Doctor of Philosophy, Leading Research Fellow, Department of the Philosophical Problems of Politics, RAS Institute of Philosophy. Postal address: 12, Goncharnaya St., Bldg. 1, Moscow, Russian Federation, 109240. Tel.: +7 (495) 697-91-89. E-mail: tatyanawings@ gmail.com 